\author{
Vladimír Moskola*, Ágnes Dóra SÁndor, Éva SusÁnSzky,

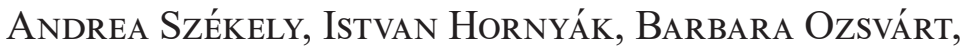 \\ TibOR NÉNINGER \& ZOLTÁN BALOGH
}

\title{
EXAMINATION OF COPING STRATEGIES AMONG ON-SITE PARAMEDICS ${ }^{* *}$
}

(Received: 26 November 2020; accepted: 28 September 2021)

The occurrence of physical and psychological symptoms that negatively influence everyday activities, efficient job performance, and professional patient treatment are common among paramedic workers. Aim: We uncovered the characteristic coping strategies applied by on-site paramedics and searched for correlations between these strategies and demographic, socio-economic characteristics, as well as factors related to work, workplace, and health behaviours.

Sample and methodology: The survey was conducted between March 1, 2018, and February 28, 2019, among employees of the DG National Ambulance Service and participants of the Chamber of Hungarian Health Care Professionals. We used an abbreviated version of the Ways of Coping Questionnaire that contains 22 items (WOC-22). Descriptive statistics, independent samples T-tests, correlation calculations, analysis of variance with the Games-Howell post-hoc test were also carried out. Results: Tension reduction was a more common coping strategy among female and/or single paramedics as well as also being characteristic of people who work as paramedic officers. Problemoriented coping stood out as a characteristic of people who have a higher level of education and/ or are more satisfied with their financial situation. Risk-seeking appears dominantly among those who are not religious and/or have a lower level of education.

Conclusions: Although paramedics are basically characterized by problem-oriented coping strategies, they quite often apply non-adaptive strategies as well; consequently, the chance of developing anxiety remains higher for them. Our aim is to use effective intervention methods for curbing the development of anxiety conditions among the ambulance personnel that have long-lasting negative effects on health care. To achieve this goal, we recommend including a questionnaire about coping strategies into the admission process of would-be paramedics; also, completing such questionnaires among the whole emergency workforce.

Keywords: coping; ambulances; paramedics; social demography; health behaviors

* Corresponding author: Vladimír Moskola, Semmelweis University Faculty of Health Sciences, Department of Oxyology and Emergency Care, Budapest; moskolva@gmail.com.

** TUKEB (Medical Research Council) permit number: 11994- /2018/EKU 


\section{Introduction}

In the case of healthcare workers and on-site paramedics, in particular, it is a wellknown fact that they are under pronounced physical and mental burden resulting in negative emotional and physiological consequences (BETLEHEM et al. 2010; PÉK et al. 2011; Szabó et al. 2008; SzоBOTA \& BALOGH 2019). This process first leads to compensation, and as time goes on and exertion continues, compensation mechanisms become inadequate, and, as a result, physical and psychological symptoms appear. The appearance of these symptoms decreases the ability for efficient and focused work, the quality of life, and increases the occurrence of family and workplace conflicts, as well as leading to serious addictions (BENNET et al. 2004; SzABó et al. 2008; HegedÜs et al. 2008). The overview of the literature on workplace conflicts shows that the so-called group effect is most common among healthcare workers in Hungary; the group effect can be interpreted as influencing cooperation within a team or among teams (e.g., paramedics and the emergency room), leading to a decrease in trust and the deterioration of workplace and professional relationships (CsUPOR et al. 2017). The above-mentioned physical and psychological effects can be characterized as conflict factors for the individual leading to the establishment of coping strategies. Coping is the result of the ever-changing interaction between personal factors and environmental effects that includes the evaluation of the stress-inducing event, the availability of the possible coping capacities, and the work necessary to carry out the chosen coping strategy (FoLKMAN \& LAZARUS 1980; 1985). Based on research results, the two most common coping strategies are the problem-solving approach and the emotional approach. During the problem-solving strategy, the focus is directly on eliminating and/or modifying the situation causing stress experience. On the contrary, the emotional approach strategy emphasizes the regulation of emotional responses to life situations causing stress. Scientific literature indicates that although to varying degrees, we use both strategies in stressful situations that require coping (RózsA et al. 2008). Conflict-solving ability as one dimension of the coping process is actively present in our everyday lives. According to RoGERs, the origin of conflict can be found between the individual's innate positive nature and the often unnatural effects of civilized society that are placed upon the individual (BUDAVÁRI-TAKÁCS 2011, 8).

In Deutsch's interpretation (Deutsch 1973), conflicts can be divided into two large groups based on their consequences and effects. The first is constructive conflict when the process ends with positive results and satisfaction. This type of conflict increases performance, reduces tension, and helps to achieve aims.

The destructive conflict, on the other hand, leaves the participant feeling a sense of loss leading to decreased performance, defensive, or introverted, closedoff behaviour (BUDAVÁRI-TAKÁCS 2011, 9). The sources of conflict are grouped into three categories: personal, interpersonal, and organizational conflicts. Our 
present research framework places the emphasis foremost on the personal aspect differentiating between two subsets of this category. The first is that of personal factors, which references the fact that the individual's personality and life situation influences the conflict, and these are related to coping styles and processes. The second subcategory includes difficulties stemming from processing loss when conflict arises in connection with losses experienced during work (for example the unexpected or sudden death of a minor/adolescent) (CSUPOR et al. 2017; RAHIM \& Bonoma 1979; LeEver et al. 2010).

The present research aims to uncover the coping strategies used by on-site paramedic workers and search for relationships between demographic and socio-economic characteristics of the examined sample as well as between factors related to work, workplace, health behaviours and coping strategies.

\section{Methodology}

\subsection{Participants}

Employees of the National Ambulance Service (NAS) who have been carrying out independent on-site work for at least six months (i.e., doctors, paramedic officers, paramedic technicians, paramedic nurses and paramedic drivers) participated in the study.

\subsection{Data collection}

Online data registration took place between March 2018 and February 2019. The questionnaire was sent to internal, closed email addresses of the NAS as well as to registered employee addresses of the National Paramedic Department in the Chamber of Hungarian Health Care Professionals (CHHCP). Of the 669 questionnaires we received, 658 could be evaluated. According to the NAS 2018 November registry data, 6,412 persons were in active employment while the questionnaire was being recorded, $88 \%$ of them were males and $12 \%$ females. The gender ratio of the study's participants was congruent with the ratio of the persons in active employment.

\subsection{Tools of assessment}

The abbreviated Ways of Coping Questionnaire, 22 item version (WOC-22).

We used the abbreviated version (KoPP \& SKRABSKI 1995; RózSA et al. 2008) of the Folkman-Lazarus questionnaire (FolKMAN \& LAZARUs 1980) applied in 
epidemiological assessments to examine conflict-solving strategies. Participants could indicate on a four-tier scale $(0=$ not at all; $3=$ completely characteristic $)$ how characteristic the coping strategies listed in the questionnaire were of them in connection with a life situation they deemed especially difficult (e.g., the death of a child or another person that affects you severely) and if the coping strategies were characteristic of them, to what degree they applied them throughout the weeks following the event. Three main coping strategies can be determined from the questionnaire: problem-oriented, emotion-oriented, and support seeking, which can be further divided into subscales. Within the problem-oriented category, we can differentiate between problem analysis, cognitive restructuring, and adaptation subscales. Within emotional orientation, we see emotionally initiated actions, seeking emotional balance and withdrawal subscales as well as the subscale of assistance-seeking within the category of support-seeking. When analyzing the data from the examined population, new subscales were determined: tension reduction, cognitive restructuring, problem analysis and risk-seeking.

Socio-demographic variables, questions regarding the workplace, work performance and financial situations were recorded in the questionnaire as well as data regarding alcohol, coffee, and energy-drink consumption in connection with lifestyles along with questions on religious beliefs.

\subsection{Statistical analysis}

Descriptive statistics were used to summarise the data; we indicated mean and standard deviation for scale variables and frequency distributions for ordinal/nominal variables. To examine differences between two groups such as men and women, religious and non-religious participants, on WOC-22 subscales, we used independent samples T-test. To examine differences between more than two groups, such as level of education, marital status, place of growing up, residential environment, workplace position, monthly working hours, type of emergency vehicle, satisfaction with the financial situation, and smoking habit, on WOC-22 subscales, we used one-way ANOVA with post-hoc tests (Games-Howell). In the case of comparing means analysis, we concluded based on the results of the robust procedure (Welch). The Spearman rank correlation coefficient was calculated to study the associations between WOC-22 subscales and the following scale or ordinal variables assuming a monotonous association: age, the number of children, time spent with the NAS, consumption of coffee, alcohol, energy drinks, and doing deliberate, active exercise. We analysed our results using the IBM SPSS Statistics for Windows, Version 25.0 (IBM Corp. Released 2017., Armonk, NY: IBM Corp.). 


\section{Results}

\subsection{Socio-demographic characteristics of the participants}

In the sample $(\mathrm{N}=669)$, just as in the full population of the profession, men are in a significant majority (87.6\%). Participants' ages ranged from 20 to 64 years $(\mathrm{M}=$ $42, \mathrm{SD}=10.41)$. A third of those who answered the questionnaire $(32.5 \%)$ were in the 36-45-year-old age group. Neither the youngest $(<25$ years) nor the oldest $(>$ 55 years) group reached $10 \%$. We used eight categories to describe qualifications. During the analysis, participants were classified into three categories based on the level of qualifications: 1) having medium-level qualifications $(23.1 \%), 2)$ having Bachelor's degree (36.8\%), 3) having Master's and/or PhD degrees (40.1\%). Most of the participants are married or live in a relationship (76.2\%), $13.7 \%$ are single and $10.1 \%$ are divorced or widowed. As regards children, those with two children were in the majority (31.2\%) and the ratio of childless individuals was $26.1 \%$. Participants spent most of their upbringing in urban environments (41.2\%). More than a third of the sample was raised in rural settings (36.5\%). At present, the majority reside in apartments that they own (42.4\%) or in detached houses with gardens that are their property $(42.3 \%)$, and $16.3 \%$ live in rented apartments or detached houses with gardens. A little over half of the participants (54.2\%) do not practise any religion.

\subsection{Characteristics related to work and workplace}

The largest percentage of NAS employees comprises paramedic nurses (46.4\%) and paramedic officers (28.1\%). Based on the time spent with the National Ambulance Service, participants have been working for six months to 44 years $(M=16.73 \mathrm{yrs}$, $\mathrm{SD}=11.36$ ); $32.9 \%$ of them have been with the NAS for $1-10$ years. The majority of the sample were employed in Central Hungary (22.7\%) and the Southern Great Plain Regions (18.6\%).

As regards the type of emergency vehicle, we saw most employees working in emergency ambulances $(45.6 \%)$ and the patient transport ambulance $(42.1 \%)$. The significant majority of those who answered the questionnaire are employed full-time $(86.2 \%)$, in 168 hours $(\mathrm{Med}=168)$. As regards work schedules, 24-hour shifts are the most common (45.8\%). When examining satisfaction with their financial situation, more than half of the respondents stated that they were moderately satisfied $(62.3 \%)$, and only $18.3 \%$ indicated that they were dissatisfied. 


\subsection{Health behaviour, risk behaviour}

A significant percentage of individuals in the sample do not smoke (67\%). When we asked about coffee-drinking habits, nearly a fifth of the participants (21.6\%) revealed they do not drink coffee. Most of those who drink coffee regularly, consume two to three cups of coffee a day (56.9\%). $27.8 \%$ of them drink four or more cups of coffee a day. The vast majority of the participants do not consume energy drinks (89.1\%). Half of the respondents do not or only rarely consume alcohol $(50.7 \%)$, the ratio of respondents who consume alcohol every day or more than once a week tallied $21.9 \%$. As regards deliberate, active exercise, those who do not or rarely exercise were in the majority, nearly half the participants $(42.4 \%)$, with 6.3 percent of employees exercising daily.

\subsection{WOC-22 questionnaire}

The confidence interval (Cronbach's alpha) of the WOC-22 subscale in the sample of on-site paramedics stood somewhat below the range of acceptability $(0.70-0.85)$. During the course of factor analysis, we were able to separate the following subscales: (1) problem analysis (questions $1,17,18,21,22)$ (2) tension reduction (questions $4,15,16,19)$, (3) cognitive restructuring (questions 8,9,10,11), (4) risk-seeking (questions $3,13)$. In the latter case, we took the fact into account that the value of Cronbach's alpha depends strongly on the item number, which means that it can even fall between 0.3-0.5. In this case, we accepted this subscale despite its lower Cronbach's alpha value.

\section{Results}

\subsection{Relationships between coping strategies and socio-demographic characteristics}

Coping strategies applied by men and women differ significantly; tension reduction is more common among women than men $(\mathrm{t}(665)=-4.301, \mathrm{p}<0.001)$.

Persons who consider themselves religious are more likely to apply cognitive restructuring in difficult life situations $(\mathrm{t}(657)=2.484, \mathrm{p}=0.013)$, while risk-seeking is more common among those who are non-religious ( $\mathrm{t}(657)=-2.449, \mathrm{p}=0.015)$.

Analysis of education levels showed a significant difference as regards the problem-oriented $(\mathrm{F}(2,658)=4.991, \mathrm{p}=0.007)$, tension reduction $(\mathrm{F}(2,658)=7.199$, $\mathrm{p}=0.001)$, and risk-seeking $(\mathrm{F}(2,658)=5.240, \mathrm{p}=0.006)$ subscales. Based on the post-hoc test (Games-Howell) it is apparent that problem-oriented coping is more 
common among $\mathrm{BSc} / \mathrm{MSc}$ graduates than in the medium-level qualifications group. Tension reduction as a coping mechanism dominates among MSc graduates and risk-seeking was a more typical coping strategy among participants with BSc degree or medium-level qualifications.

When examining marital status, we found a significant difference as regards tension reduction $(\mathrm{F}(2,653)=7.897, \mathrm{p}=0.001)$, it is more common among single persons than among divorced or widowed participants.

Age and problem-oriented coping strategy $(\mathrm{rho}(663)=-0.098, \mathrm{p}=0.012)$, as well as tension reduction $(\mathrm{rho}(663)=-0.185, \mathrm{p}<0.001$ ) showed a statistically significant correlation but the effects were negligible/very small. There is no association between age and coping strategies.

A statistically significant correlation did exist, however, between the number of children and tension reduction $(\mathrm{rho}(626)=-0.134, \mathrm{p}<0.001)$. The effect was very small: there is no association between the number of children and coping strategies.

In further questions such as 'Where did you spend the most time growing up?', 'What sort of residential environment do you live in?', we did not find significant differences/associations on the subscales of the questionnaire (Table 1).

\subsection{Relationships between coping strategies and work/workplace characteristics}

As regards workplace position, a significant difference existed between tension reduction $(\mathrm{F}(3,640)=5.317, \mathrm{p}=0.002)$ and risk-seeking $(\mathrm{F}(3,640)=3.582, \mathrm{p}=$ $0.017)$, but in the post-hoc test, a significant difference was only seen in tension reduction, thus we can ascertain that tension reduction is most characteristic of paramedic officers.

As regards monthly working hours, there was a statistically significant correlation with tension reduction but the effect remained negligible (rho $(652)=-0.097$, $\mathrm{p}=0.013$ ). In summary, there was a non-significant association between monthly working hours and coping strategies.

When examining satisfaction with the financial situation, we found a significant difference between examined groups (satisfied, moderately satisfied, dissatisfied) on problem-oriented coping strategies $(\mathrm{F}(2,657)=4.760, \mathrm{p}=0.009)$. Participants satisfied with their financial situation showed a higher score than those moderately satisfied or dissatisfied.

Time spent working as a paramedic showed a statistically significant correlation with problem-orientation $(\mathrm{rho}(636)=-0.119, \mathrm{p}=0.003)$ and tension reduction $($ rho $(636)=-0.093, p=0.018)$. However, the correlation coefficients imply very small or negligible associations; there were no associations between time spent working as a paramedic and coping strategies. 
In questions such as 'What level of care the vehicle can provide that you work in and with what kind of work schedule do you have?', we did not find significant differences/associations on the subscales of the questionnaire (Table 1).

\subsection{Relationships between coping strategies and health/risk behaviour characteristics}

Alcohol consumption and cognitive restructuring showed a statistically significant correlation but the correlation coefficient stood at almost zero $(\operatorname{rho}(653)=-0.083$, $\mathrm{p}=0.033)$. There was a non-significant association between alcohol consumption and coping strategies.

Finally, doing active, deliberate exercise showed a statistically significant association with tension reduction $(\operatorname{rho}(650)=-0.118, \mathrm{p}=0.002)$ and cognitive restructuring $(\operatorname{rho}(650)=0.132, \mathrm{p}<0.001)$, but the effects were very small. There was a non-significant association between doing active, deliberate exercise and coping strategies.

Finally, there appears a non-significant correlation/difference between coping strategies and coffee, energy drinks consumption, as well as smoking habits (Table 1).

\section{Table 1}

Relationships between WOC-22 subscales and socio-demographic factors, characteristics related to work/workplace, as well as health/risk behaviours

\begin{tabular}{|c|c|c|c|c|}
\hline \multicolumn{5}{|c|}{ WOC-22 subscales } \\
\hline & $\begin{array}{l}\text { Problem- } \\
\text { oriented }\end{array}$ & $\begin{array}{l}\text { Tension } \\
\text { reduction }\end{array}$ & $\begin{array}{l}\text { Cognitive } \\
\text { restructuring }\end{array}$ & $\begin{array}{c}\text { Risk- } \\
\text { seeking }\end{array}$ \\
\hline \multicolumn{5}{|c|}{ Socio-demographic factors } \\
\hline gender & ns & $x$ & ns & ns \\
\hline religiosity & ns & ns & $x$ & $x$ \\
\hline education & $x$ & $x$ & ns & $x$ \\
\hline marital status & ns & $x$ & ns & ns \\
\hline age & ns & & & \\
\hline number of children & ns & & & \\
\hline place of growing up & ns & & & \\
\hline residential environment & ns & & & \\
\hline
\end{tabular}


Work and workplace characteristics

workplace position
monthly working hours
satisfaction with the financial situation

time spent with the NAS

type of emergency vehicle

work schedule

Health/risk behaviour

alcohol consumption

doing active, deliberate exercise

coffee consumption

energy consumption

smoking habits ns

Note. x: significant difference/association; ns: non-significant difference/association.

\section{Discussion}

During our study, we attempted to determine - based on the internationally used Folkman and Lazarus Questionnaire (WOC-22) - the sort of coping strategies that are characteristic among professionals carrying out on-site emergency healthcare work. We also sought to find out relationships between the discovered coping strategies and socio-demographic, workplace, and health-influencing factors. No survey on the topics and to this extent had been carried out among paramedics in Hungary before. In Poland Kosydar-BocheneK and colleagues (2017) conducted such a study. In Hungary, ScHISzLER and colleagues (2016) investigated coping among paramedics, but from a different aspect. We identified four different coping strategies in our sample: problem-oriented, tension-reduction, cognitive restructuring, and risk-seeking. These show many similarities to the WOC 16 questionnaire scale structure used in the high-element-number Hungarostudy 2002 with a civilian sample (Kopp \& Kovícs 2006).

During our study, we ascertained that tension reduction is more common among women. Different studies have yielded contradicting results in this matter, according to a Hungarian study conducted by MARTON-SIMORA and colleagues 
(2008), there is no gender difference when coping with stress; however, a British study by BENETT and colleagues (2004) indicates that workplace stress affects male paramedics more significantly than female paramedics, thus there is a difference between coping strategies. Furthermore, a connection can be determined between college education, unmarried persons, and paramedic officers, which indicates that tension reduction is more common among paramedics at the beginning of their careers. At the same time, we did not find any relationships between coping strategies and factors related to health/risk behaviour among on-site paramedics. Emergency workers who dominantly use cognitive restructuring are religious. Among others, the results of the study conducted by PAVENKov and colleagues (2016) show that certain coping strategies are in correlation with the levels of religious faith because the more the person is likely to apply tension reduction, the stronger their religious conviction is. In connection with problem-oriented coping, we see a relationship with a higher level of education, being satisfied with one's financial status, and being inexperienced (having spent the least amount of time or years at their workplace). We see concrete influencing factors characteristic of certain coping subscales come to the forefront; this provides us with the possibility to carry out predisposing surveys in the future to screen for those who use negative coping methods so that we can provide help to prevent negative consequences. We would like to emphasize here that the results of the present study are based on a cross-sectional design, which does not mean causal relationships between examined factors and coping strategies - thus the conclusions should be handled with caution. In the interest of deeper observations to provide confirmation of our observations, we expect further examinations on the topic in the future.

\section{Conclusion}

Although paramedics are basically characterized by problem-oriented coping strategies, they quite often apply non-adaptive strategies as well; consequently, the chance of developing anxiety is higher among them. Our aim is to use effective intervention methods for curbing the development of anxiety conditions among the ambulance personnel that have long-lasting negative effects on health care. To achieve this goal, we recommend including a questionnaire about coping strategies into the admission process of would-be paramedics; also, completing such questionnaires among the whole emergency workforce. 


\section{References}

Bennett, P., Y. Williams, N. Page, K. Hood \& M. Wollard (2004) 'Levels of Mental Health Problems Among UK Emergency Ambulance Workers', Emergency Medicine Journal 21(2), 235-36 (https://doi.org/10.1136/emj.2003.005645).

Betlehem, J., A. Horváth, Zs. Göndöcs, S. Jeges, I. Boncz \& A. Oláh (2010) 'Major Contributing Factors of Self Perceived Health in Hungarian Ambulance Personnel', Orvosi Hetilap, 151(51), 2089-98 (https://doi.org/10.1556/ oh.2010.28976).

BudAVÁRI-TAKÁCS, I. (2011) A konflikutiskezelés technikái [Conflict management techniques] (Budapest: Szent István Egyetem) note 8.

BudAVÁri-TAKÁCs, I. (2011) A konflikutiskezelés technikái [Conflict management techniques] (Budapest: Szent István Egyetem) note 9.

Csupor, É., Á. Kuna, J.N. Pintér, Zs. Kaló \& M. Csabai (2017) 'Konfliktustípusok és konfliktuskezelés magyar egészségügyi dolgozók körében’ [Conflict types and conflict management among Hungarian healthcare workers], Orvosi Hetilap 158(16), 625-33 (https://doi.org/10.1556/650.2017.30736).

Deutsch, M. (1973) The Resolution of Conflict, Constructive and Destructive Processes (New Haven: Yale UP) (https://doi.org/10.1177/000276427301700206).

Folkman, S. \& R.S. Lazarus (1980) 'An Analysis of Coping in A Middle-Aged Community Sample', Journal of Health and Social Behavior 21(3), 219-39 (http://doi.org/10.2307/2136617).

Folkman, S. \& R.S. Lazarus (1985) 'If it Changes it Must Be Process: Study of Emotion and Coping During Three Phases of a College Examination', Journal of Personality and Social Psychology 48(1), 150—70 (https://doi.org/10.1037//00223514.48.1.150).

Hegedüs K., N. Szabó, G. Szabó \& M. Kopp (2008) 'Egészségesebbek-e az egészségügyben dolgozók? Összehasonlító vizsgálat (2002-2006)' [Are healthcare workers healthier? Comparative study (2002-2006)] Növér 21(1), 3-9.

Kosydar-Bochenek, J., D. Ozga, K. Wozniak, M. Migut, B. Lewandowski \& D. Burdzy (2017) 'Traumatic Stress in the Work of Paramedics', Przeglad epidemiologiczny 71(4), 639-45.

Kopp, M. \& Á. SkrabSKi (1995) Magyar lelkiállapot (Budapest: Végeken).

Kopp M., M.E. Kovács (2006), eds, A magyar népesség életminősége az ezredfordulón (Budapest: Semmelweis).

Leever, A.M., M.V.D. Hulst, A.J. Berendsen, P.M. BoendemaKer, J.L.N. RoodenburG \& J. Pols (2010) 'Conflicts and Conflict Management in the Collaboration Between Nurses and Physicians - A Qualitative Study', Journal of Interprofessional care 24(6), 612-24 (https://doi.org/10.3109/13561820903550762). 
Marton-Simora J., O. Gyermán, G. Nagy, K. Deutsch, Z. Göndöcs \& J. Betlehem et al. (2008) 'Poszttraumás stressz a budapesti mentődolgozók körében' [Posttraumatic stress among ambulance workers in Budapest], Növér 21(4), 10-19.

Pavenkov, O., I. Shmelev \& M. Rubtcova (2016) 'Coping Behavior of Orthodox Religious Students in Russia', Journal for the Study of Religions and Ideologies 15(44), 205-24.

Pék, E., G. Nagy, J. Marton-Simora, K. Deutsch, B. Radnai, J. Szabó \& J. Betlehem (2011) 'Élvezeti szerek és Poszttraumás stressz szindróma összefüggései mentődolgozók körében' [Rescue workers among drug use and post-traumatic stress syndrome in context], Növér 24(4), 11-20.

Rahim, M. \& T.V. Bonoma (1979) 'Managing Organizational Conflict: A Model for Diagnosis and Intervention', Psychological Reports 44(3), 1323-44 (https:// doi.org/10.2466/pr0.1979.44.3c.1323).

Rózsa, S., Gy. Purebl, E. Susánszky, N. Kö, E. Szádóczky, J. Réthelyi, I. Danis, Á. SkrabsKi \& M. Kopp (2008) 'Dimensions of Coping: Domestic Adaptation of the Conflict Resolution Questionnaire', Mentálhigiéné és Pszichoszomatika 9(3), 217-41(https://doi.org/10.1556/mental.9.2008.3.3).

Schiszler, B., A. Karamánné Pakai, Z. Szabó, L.B. Raposa, R. Pónusz, B. RADNAI \& D. ENDREI (2016) 'Munkahelyi stressz és megküzdési stratégiák vizsgálata földi és légi mentésben dolgozók körében' [Investigation of workplace stress and coping strategies among ground and air rescue workers], Orvosi Hetilap 157(45), 1802-08 (https://doi.org/10.1556/650.2016.30581).

Szabó, N., K. Hegedüs, G. Szabó, M. Kopp (2008) 'Egészségügyi dolgozók munkahelyi stressz-állapota és társas támogatottsága' [Work-related stress status and social support for health care workers] Növér, 21(1), 10-17.

SzoвотA L. \& Z. BALOGH (2019) 'Az egészségkárosító kockázatok ismerete az egészségügyi szakdolgozók körében' [Knowledge of health hazards among health professionals] Lege Artis Medicinae 29(12), 615-22, retrieved 14 Oct 2021 from LAM_2019_12.pdf (mtak.hu). 